\title{
The Aesthetic Dimensions of U.S. and South Korean Responses to Web Home Pages: A Cross-Cultural Comparison
}

\author{
Anthony Faiola, Chin-Chang Ho, Mark D. Tarrant, \\ and Karl F. MacDorman \\ Indiana University School of Informatics, Indianapolis
}

\begin{abstract}
Culturally influenced preferences in website aesthetics is a topic often neglected by scholars in human-computer interaction. Kim, Lee, and Choi (2003) identified aesthetic design factors of web home pages that elicited particular responses in South Korean web users based on 13 secondary emotional dimensions. This study extends Kim et al.'s work to U.S. participants, comparing the original South Korean findings with U.S. findings. Results show that U.S. participants reliably applied translations of the emotional adjectives used in the South Korean study to the home pages. However, factor analysis revealed that the aesthetic perceptions of U.S. and South Korean participants formed different aesthetic dimensions composed of different sets of emotional adjectives, suggesting that U.S. and South Korean people perceive the aesthetics of home pages differently. These results indicate that website aesthetics can vary significantly between cultures.
\end{abstract}

\section{INTRODUCTION}

Since the mid-1990s, the globalization of the Internet has become the source of numerous difficulties for communication technologists (Igbaria \& Zviran, 1996; Omar, 1992). The strategic planning of website design and especially web accessibility and usability have become a challenge to developers because of their limited knowledge of cultural preferences. In an effort to refine their approach to these hurdles, cross-cultural scholars in human-computer interaction (HCI) have identified cultural preference as having a direct impact on the aesthetic aspects of web design and usability (Angeli, Sutcliffe, \& Hartmann, 2006; Faiola \& Matei, 2005; Hillier, 2003; Lavie \& Tractinsky, 2004).

This article first describes the importance of aesthetics in website design (Ben-Bassat, Meyer, \& Tractinsky, 2006; Picard, 1997) and outlines how website aesthetics, when properly implemented, can result in positive interactions for users

Correspondence should be addressed to Anthony Faiola, Indiana University School of Informatics, Informatics Complex, Room IT 485, 535 West Michigan Street, Indianapolis, IN 46202. E-mail: faiola @iupui.edu

This is the author's manuscript of the article published in final edited form as: Faiola, A., Ho, C. C., Tarrant, M. D., \& MacDorman, K. F. (2011). The aesthetic dimensions of US and South Korean responses to web home pages: A cross-cultural comparison. Intl. Journal of Human-Computer Interaction, 27(2), 131-150. http://dx.doi.org/10.1080/10447318.2011.537173 
(Angeli et al., 2006; Hartmann, 2006; Schenkman \& Jonsson, 2000). The article further argues that home pages give web users their first impression of an organization (Schenkman \& Jonsson, 2000), serve as a branding instrument (Geissler, 1998), and elicit aesthetic responses (Gobé, 2001; Travis, 2000). The article then outlines the specific theoretical underpinning of the empirical study presented here. A study conducted by Kim, Lee, and Choi (2003) informs the aesthetic aspect of this article by identifying several home page design factors and their corresponding secondary emotions within a South Korean population.

Consequently, the question arises whether Kim et al.'s findings for South Korean participants would match the responses of U.S. participants. The study presented here tested U.S. participants using Kim et al.'s original methodology and web home pages and compared their results with those of this study. U.S. participants reliably applied translations of the emotional adjectives used in the Kim et al. study to the home pages. However, further data analysis revealed that the aesthetic perceptions of U.S. and South Korean participants formed different dimensions composed of different sets of adjectives. These results indicate cross-cultural differences in aesthetic responses to home pages.

\section{CROSS-CULTURAL EMOTIONAL RESPONSE TO AESTHETICS}

\subsection{Emotion and Cross-Cultural Cognition}

Many emotion theorists subscribe to the psycho-evolutionary view that emotions are evolving evaluative patterns that enable a quick and efficient response to environmental events (Rosenberg, 1998). Building on this theory, Gratch and Marsella (2005) have proposed that action selection as an emotional response is a mechanism that helps humans perceive and categorize significant environmental events. They also suggested that this appraisal process is inherently reflective, being informed by cognition, which includes understanding; interaction with the environment; and the activation of perceptual, memory, and linguistic processes.

Just as the emotional appraisal process is informed by cognition, a number of studies in cross-cultural psychology and cultural anthropology have shown that cognition, in turn, reflects the cultural context (Cole, Gay, Glick, \& Sharp, 1971; Hofstede, 1980, 1991; Nisbett \& Norenzayan, 2002). Many topics have been investigated from the standpoint of cross-cultural cognition, but the dynamics of human emotion provide a uniquely rich perspective on the differences that exist across diverse cultures. Numerous studies have shown both cultural differences and cultural universals with respect to emotion (Ekman, 1992; Matsumoto \& Ekman, 1989; Rosenberg \& Ekman, 1994).

An example of the dynamics of emotion is a study conducted by Faiola and Matei (2005) in which participants expressed preferences for websites based on their particular cultural bias. In this case, human bias and emotion affected complex processes of appraisal and subjective evaluation as participants viewed websites developed by designers of various cultural backgrounds. The study shows how emotion and culture are inextricably linked in their effect on our appreciation and appraisal of websites and the aesthetic elements they display. 


\subsection{Cross-Cultural Secondary Emotion and Aesthetics}

Users unconsciously tap into their emotions as they appraise websites in the context of their personal desires, intentions, and past events. This emotional undercurrent strongly influences users' preferences for websites (Gratch \& Marsella, 2005). Norman (2004) referred to this kind of preference as being driven by emotion as a reflective operation of cognition. Norman also stated that the reflective level of cognition is the most "vulnerable to variability through culture, experience, education, and individual differences" (p. 38).

Researchers continue to examine the influence of culture on web design by comparing users from diverse cultures (Burnett \& Buerkle, 2004; Dou, Nielsen, \& Ming, 2002; Hillier, 2003; Yetim \& Raybourn, 2003; Zahedi, van Pelt, \& Song, 2001). The resulting trends and data comparisons illuminate the influence of cultural cognition on web developers and users. We believe that in the future web designers will increasingly take into account the complexity of the cognitive and emotional apparatus that facilitates cross-cultural web use.

Emotion theory differentiates between primary (Ekman, 1999) and secondary emotions (Gaunt, Leyens, \& Demoulin, 2002) and among emotional dimensions (Buck, 1999; Ekman, 1992). Izard (1971) identified anger, contempt, disgust, distress, fear, guilt, interest, joy, shame, and surprise as primary or basic emotions. Oatley and Johnson-Laird (1987) limited the set to anger, disgust, happiness, and sadness. Ekman (1999) considered 15 emotions to be primary. Although scholars disagree on which emotions are primary and the demarcation between primary and secondary emotions, a common understanding of the issue has formed. Primary emotions, universal to all humans, are expressed with adjectives, such as amusement, anger, contempt, contentment, disgust, embarrassment, excitement, fear, guilt, pride in achievement, relief, sadness and distress, satisfaction, sensory pleasure, and shame (Ekman, 1999). Secondary emotions, which derive from primary emotions, depend on the individual and the context or domain (Averill, 1994). Strong evidence for distinguishing various emotions comes from Ekman's (1992) research on facial expressions, and although research suggests that most emotional expressions are universal, the social contexts that draw forth emotions differ across cultures.

Although Doost, Moradi, Tagahavi, Yule, and Dalglesh (1999) have identified thousands of adjectives to describe secondary emotions, Averill (1994) maintained that emotional dimensions are different according to individual characteristics and might be expressed in a range of experiences specifically related to an aesthetic response to a piece of art or a website (Cupchik, 1994; Frijda, 1989). One cross-cultural difference is the more accurate recognition of emotional expression within a particular culture (Biehl et al., 1997; Boucher \& Carlson, 1980; Matsumoto, 1992; Matsumoto \& Ekman, 1989; McAndrew, 1986). We propose that cross-cultural aesthetic experience invokes a secondary emotional response. This response can be measured by assigning a numeric value to a semantic differential scale from which users select the appropriate responses as they view websites. As previously described, a cross-cultural comparison of secondary emotions of users responding to website home pages is the focus of this study. 


\section{THE IMPACT OF AESTHETICS ON WEB DESIGN}

\subsection{Identifying Aesthetic Elements and Responses}

A number of aesthetic elements can evoke emotional responses from people who view websites. However, the identification of those elements by empirical studies has only recently begun. The investigation of the relation between home page design elements and emotional responses is in its infancy (Angeli et al., 2006; Lavie \& Tractinsky, 2004). Most research performed on responses to aesthetic elements has been in film and television, using techniques like film grammar and applied media aesthetics (Dorai \& Venkatesh, 2002; Zettl, 2002). Unfortunately, these methods and techniques do not readily transfer to web pages.

A key study of web-based aesthetics was conducted by Schenkman and Jonsson (2000), who examined the relation between aesthetics and preferences by having participants judge web pages according to several parameters, including complexity, legibility, order, beauty, meaningfulness, and comprehension. Although they found "a combination of pictures and beauty" (p. 375) to be a strong preference, they did not explore the emotional impact of specific design elements.

A body of research suggests that a pattern or combination of elements, as opposed to a single element, is more likely to induce a desired response reliably (Arnheim, 1986; Brave \& Nass, 2003; Hartmann, 2006; Picard, 1997). For example, Kim and Moon (1997) found that very specific combinations of web interface color and artwork evoked feelings of trustworthiness for cyber banks. Such efforts are akin to computer pattern recognition-assigning stimuli (e.g., vocalizations, facial expressions, and gestures) to specific categories (Picard et al., 2004).

Color is an especially important element of aesthetics, because it influences the nervous system and stimulates aesthetic responses in the brain (Gobé, 2001). Although determining an individual's response to particular color elements can be challenging, "carefully designed color schemes [combined with other design elements] can produce reliable and specific influences on mood" (Brave \& Nass, 2003, p. 88). In addition, Zettl (2002) found that the coldness or warmth of a color can affect mood.

Typefaces can also carry significant aesthetic weight, because they affect how users feel about the ideas in the text they are interacting with. Gobé (2001) and Watzman (2003) observed that typefaces can convey an aesthetic message (Bickmore \& Picard, 2005; Reeves \& Nass, 1998). Fogg (2003), for example, created a dominating interface that employed only "bold, assertive typefaces for the text" (p. 96) and caused very recognizable user responses.

After reviewing the available literature on web interfaces and aesthetics, Karvonen (2000) concluded that almost all studies had simply "made up" their parameters "without any justification from existing theories of the aesthetic" (p. 86). She also argued that a "formal analysis" of aesthetic elements would provide web page designers with more useful tools. Tractinsky (2004), likewise, found that rather broad measures were employed in most aesthetics studies of web pages. With so many potential aesthetic elements to combine on web home pages, Zettl (2002) suggested that designers need a pattern-recognition framework to control aesthetic elements. 


\subsection{Aesthetics and Usability}

Although harnessing aesthetic effects is a crucial step toward more precisely targeted web design, it is important to also consider the effects of graphic elements on usability and overall user-system interaction. For example, in hyperinteractive, three-dimensional games like Halo and World of Warcraft, it is especially important to control aesthetic elements while remaining mindful of usability to ensure a satisfying user experience (Pagulayan, Keeker, Wixon, Romero, \& Fuller, 2003). Going beyond usability considerations, Lavie and Tractinsky (2004) argued that aesthetics may be the single most important factor in influencing how other website characteristics, such as usability, credibility, and memorability, are perceived. 175 Hence, "aesthetic considerations should [be] blueprints for design activities," that is, special attention should be paid to how aesthetics relate to and inform other design elements (Tractinsky, 2004, p. 777).

Researchers have become increasingly confident that aesthetic factors have a pronounced impact on interaction design. Norman (2004) stated that aesthetics inform attractive products to make people feel good, and whereas Sutcliffe (2003) has already argued that designing with primarily aesthetics in view serves to attract users, Norman contended that aesthetics might be even more important to users than more practical aspects of design, such as usability. Norman further identified part of the aesthetic solution as visceral design, which produces an immediate emotional impact on users and "requires the skills of the visual and graphic artist and the industrial engineer" (p. 69). As the power of aesthetics becomes increasingly documented, many researchers have encouraged designers to satisfy their users by producing interfaces that induce positive feelings based on design choices that are sensitive to aesthetics. This advice has largely been neglected as many web developers continue to focus primarily on functionality and usability (Gobé, 2001).

Because user preferences are largely driven by emotion, an exclusive concern for usability results in design that may be usable but not enjoyable (Blythe, Overbeeke, Monk, \& Wright, 2004; Norman, 2004). Moreover, traditional cognitive approaches to website usability have tended to underestimate the dramatic influence of emotion on user preferences. The design of a website can result in aesthetic appeal, pleasure, and satisfaction for the user (Spiller, 2005). As Norman asserted, affect is closely linked to attitudes, expectations, and motivations and produces an emotional response that plays a significant role in user cognition. These emotional states of subjectivity mediate specific aspects of user interaction with the design of a website. It is possible that emotion dominates what might be a purely cognitive process that results in a response to visual stimuli. For example, if a designer makes a web interface too simple, the user is bored, and if the interface is too complex, the users feel overwhelmed (Hassenzahl, Platz, Burmester, \& Lehner, 2000).

Home pages, as the first pages typically seen on the site, can determine whether visitors wish to spend more time exploring the site. In fact, such first impressions may be key to understanding many subsequent user judgments regarding their visiting and remaining at a site (Ben-Bassat et al., 2006). As a result, a good first impression may offer an important incentive for visitors to remain at a website. At 
the same time, a less-than-appealing home page may prompt several reasons for a low response rate (e.g., lack of attractiveness or impression of not being truthful). Gobé (2001) attributed some of this apathy to a lack of aesthetic attraction, whereas Fogg (2003) attributed it to a lack of credibility. There are many researchers who believe appearance is crucial in helping users bond with a web interface while feeling emotionally satisfied with it (Angeli et al., 2006; Cyr \& Trevor-Smith, 2004).

In summary, although websites that are well organized are necessary to help eliminate misunderstandings, attractive websites motivate users to linger and return (Bickmore \& Picard, 2005; Zettl, 1990). These views underscore the importance of eliciting a positive emotional response with the aesthetic design of a website. The desired outcome is that the site would capture the attention of users, convey the intended message of the home page, and persuade users to remain at the website. Brave and Nass (2003) described these aesthetically derived benefits in terms of better attention, memory, performance, and assessment. Similarly, Gobé (2001) proposed that for websites to attract people, designers must create the correct aesthetic allure for every interaction. Fogg (2003) elaborated further by emphasizing that one key element in "surface credibility is visual design. [e.g.,] . . . the colors, the layout, the images, and other design elements" (p. 168).

\subsection{Design Preferences from a Cross-Cultural Perspective}

Websites designed for international users have often been criticized, because they appear to be little more than slightly modified U.S. designs that ignore the preferences of other cultures (Badre, 2000; Chau, Cole, Massey, Montoya-Weiss, \& O'Keefe, 2002; Faiola \& Matei, 2005; Kamppuri, Bednarik, \& Tukiainen, 2006; Shen, Woolley, \& Prior, 2006; Simon, 1999). These preferences are important because culture, personality, and emotion have been found to influence how people learn and interact with online information (Badre, 2000; Marcus, 2003; Nisbett, 2003; Norman, 2004; Picard et al., 2004; Simon, 1999; Tractinsky, 2004). This learning process, in turn, influences how users interpret a website's aesthetics (Karvonen, 2000; Lavie \& Tractinsky, 2004; Zettl,1990).

Although most cultural traits are embedded in human cognitive development, instantaneous experiences of emotion can change behavior over a relatively short period (Norman, 2004). Norman (2004) stated that "everything has both a cognitive and an affective component-cognitive to assign meaning, affective to assign value" (p. 25). In other words, affect becomes the process of making judgments on what is good or bad, liked or disliked. Websites are just one example of those experiences that activate cultural preferences. Many design elements (e.g., colors, borders, backgrounds, images, circles, rectangles, and lines) are classified as cultural markers found in web pages that "prove to be highly prevalent within a particular cultural group" (Badre, 2000, p. 5). Likewise, Simon (1999) found that Asians disliked triangles and squares on web pages, whereas North Americans and Europeans preferred combinations of those shapes. Many studies have found cultural preferences in web page design and aesthetics (Chau et al., 2002; Cyr \& Trevor-Smith, 2004; Singh, Fassott, Zhao, \& Boughton, 2006). 
The aforementioned studies have demonstrated the effect of culture on web design, whereas other studies have examined the influence of aesthetics on web design (Angeli et al., 2006; Hartmann, 2006; Heijden, 2003; Karsvall, 2002; Kim et al., 2003; Lavie \& Tractinsky, 2004; Nakarada-Kordic \& Lobb, 2005; Schenkman \& Jonsson, 2000). These latter studies, however, are not cross-cultural. In fact, aside from acknowledging that cultural context influences web design aesthetics, aesthetic dimensions are hardly mentioned. One exception is Karvonen (2000), who showed that Finnish and Swedish participants associated clean and simple web designs with trustworthiness.

What follows is our investigation into the feasibility of applying aesthetic preferences of web pages to diverse cultural groups. Based on the resulting conclusion, web designers can begin to learn what specific aesthetic ground rules can be applied to a given cultural context. This inquiry is relevant, because cross-cultural research has shown that participants from different cultures perceive web pages differently and often prefer different designs (Faiola \& MacDorman, 2008).

One attempt to relate the design of web home pages to participants' aesthetic dimensions was the research of Kim et al. (2003), conducted in South Korea with home pages using Korean Hangul fonts. This study, however, did not compare the aesthetic dimensions for web home pages among participants of diverse national cultures. Consequently, no certainty exists that any of their findings for South Korean participants would generalize to U.S. participants. Moreover, if the research design of Kim et al. could be applied to U.S. participants with positive results, designers in the U.S. might have additional means to support web home page development and image branding.

This deficiency of cross-cultural research that explicitly compares web aesthetics begs the question: If the aesthetic design elements of a web page reveal preferences within an Eastern single-culture population (e.g., South Korea), would the same elements reveal the same preferences within a Western population (e.g., the United States)? More specifically, would U.S. participants use the same (translated) emotion-related adjectives to express the same aesthetic dimensions when browsing South Korean home pages?

\section{RESEARCH QUESTIONS AND HYPOTHESES}

\subsection{Basic Elements of the Kim et al. Study}

Originally, the Kim et al. (2003) findings were drawn from three related empirical studies to "identify the quantitative relations between secondary emotional dimensions and home page design factors" (p. 904), as created by South Korean designers. The three studies are briefly described here:

1. The purpose of Study 1 was to "identify the major dimensions of secondary emotions that people usually feel when viewing diverse home pages" (p. 904). The first study involved collecting and winnowing adjectives that described home pages, resulting in 278 applicable words. This consisted of a brainstorming study with design experts and a survey study with home page users to identify 
13 emotional dimensions measured by 30 representative emotive adjectives. Kim et al. claimed that the 13 aesthetic dimensions they identified were "stable regardless of different home pages and different users" (p. 922). Kim et al. also claimed that they determined the particular elements of home pages that consistently evoked "secondary emotions" (p. 903) as expressed by adjective selections, such as cute, vibrant, mystic.

2. The purpose of the second study was twofold-first to "prepare sample home pages for each of the 13 emotional dimensions identified in the first study" and next to identify the most significant "visual design factors of home pages from a designer's perspective" (p. 908). The second study directed 36 professional web designers, placed in 13 groups, to each create four unique home pages for each of the 13 emotional dimensions identified in the first study. The designers arranged the web pages they created into "categories according to the emotions that the individual pages induced" (p. 905). Based on personal interaction with the home pages and using cluster and factor analysis, the 13 design groups indentified one representative home page that best expressed each aesthetic emotive scale, with a nal set of 13 home pages.

3. The goal of the third study was to "identify quantitative relations between the design factors identified in the second study and the emotional dimensions identified in the first study" (p. 912). In the third study, 418 South Korean participants viewed the 13 representative home pages and identified their immediate aestheticcentric feelings using emotive scales derived from the 278 applicable words. This last study was conducted as an online survey with home pages from the second study to identify the quantitative relations between the secondary emotional dimensions and design factors for the South Korean home pages.

Extending the Kim et al. study. To examine correlations of cross-cultural aesthetic preferences between the findings of the South Korean participants (Kim et al., 2003) and U.S. participants, the investigators extended the Kim et al. study. To do this, they observed whether the representative South Korean home pages evoked similar aesthetic responses in U.S. participants. The home pages of the South Korean study were presented to U.S. participants without modification or translation.

As a convenient means to explore key findings of the Kim et al. (2003) study, the authors patterned their study similarly by using the 30 representative emotive adjectives from Kim et al.'s first study, translated into English, and the 13 home pages from the second study to determine the aesthetic responses of U.S. participants as they identified South Korean-designed home pages. It is important to note that the Kim et al. study identified these 13 home pages as highly representative of the statistically controlled larger group of 52 home pages.

\subsection{Hypotheses}

The broader research questions addressed are twofold. First, what adjectives best capture a U.S. participant's sense of aesthetics when browsing the same home 
pages viewed by the South Korean participants from the original Kim et al. study? Second, what factors are involved in explaining how U.S. visitors react to home pages? Examples could include color contrast, navigation bars, icons, frames, and typography. From these general research questions we modeled two specific hypotheses from which to frame our study:

H1: U.S. and South Korean participants will consistently use adjectives of emotional dimensions with similar meanings to describe home pages that are representative of South Korean web design.

H2: U.S. and South Korean participants will apply adjectives with different meanings for each aesthetic dimension while viewing the same home pages that are representative of South Korean web design.

\section{METHOD}

\subsection{Participants}

For this study, 107 U.S. adults were drawn from the general population of central Indiana, of which 54 participants completed the entire survey. The participants were $41.7 \%$ male and $93.5 \%$ were older than 31 . All participants grew up speaking English as their first language. Participants, by means of an e-mail invitation, were asked to participate in an online web-based survey.

\subsection{Treatment}

The web home page used for this study contained the same images used in the original study by Kim et al. (2003). Each of the 13 original South Korean home pages were displayed 29 times with a new adjective set beside each image, that is, each image was repeated to ensure that the participants could always see the home page as they scrolled down and evaluated the adjective sets. The next 12 pages followed the same pattern except they displayed a different home page (Figure 1). Finally, demographic questions appeared related to gender, age, language, and color-blindness.

Participants clicked on the link provided in the invitation e-mail to display the web survey site. After participants studied and agreed to the consent form, the site displayed the web survey. All home pages were viewed online by clicking radio 370 buttons for responses. The emotive adjective sets were ranked using a 7-point Likert scale, and the participants could only click one of seven radio buttons that best expressed the aesthetic fit of the adjective to the home page.

Participants were asked to rank the 30 adjectives, which were translated from Korean, according to their immediate feelings when viewing each home page. The emotive adjectives were adorable, balanced, bright, calm, classical, colorful, concise, conventional, cute, deluxe, elegant, familiar, fresh, futuristic, hopeful, mystic, plain, popular, powerful, promising, sexy, sharp, simple, static, strong, surreal, tense, vague, valuable, and vibrant. 

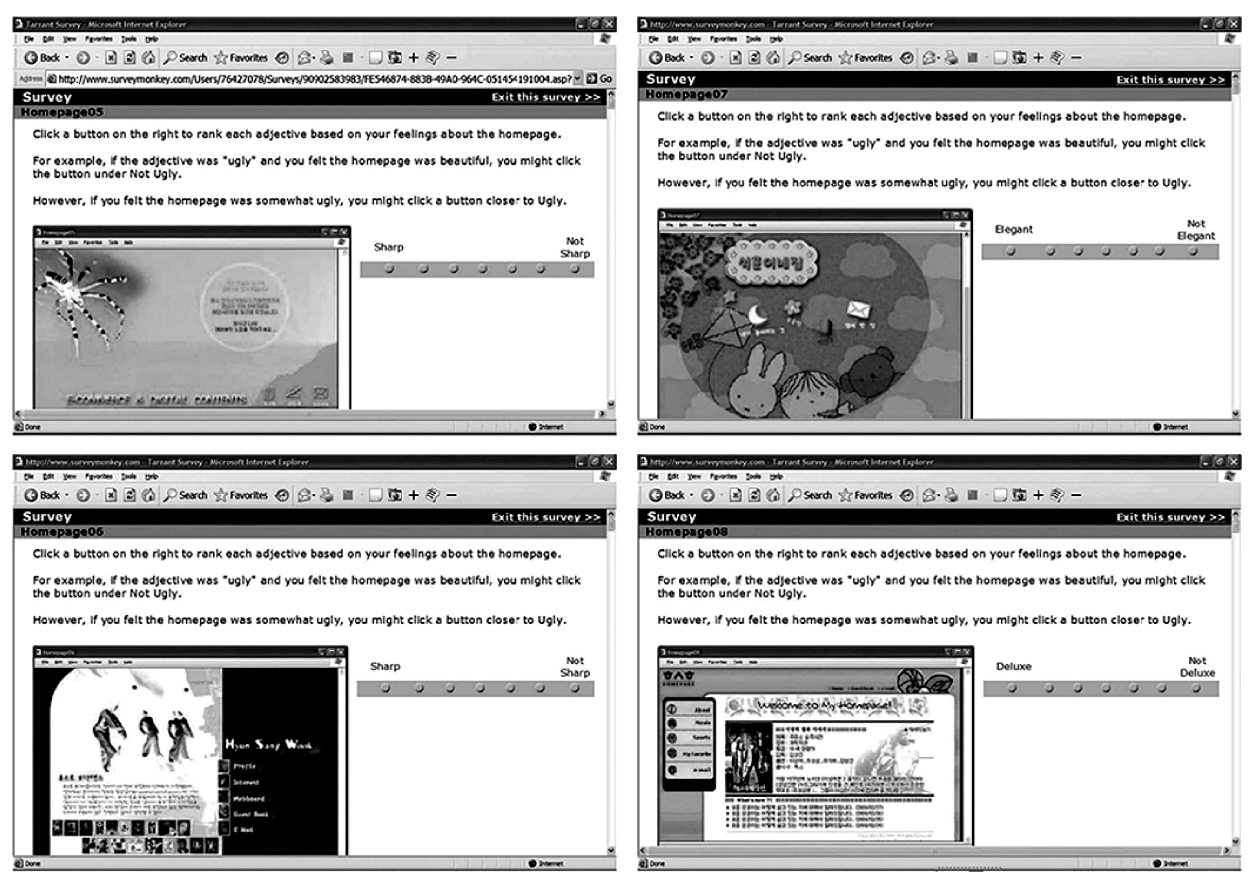

FIGURE 1 The figure shows the home page alongside the emotive adjective sets with the 7-point Likert emotive scale from which the U.S. participants could click one of seven radio buttons that best expressed their personal aesthetic response.

\subsection{Data Analysis}

Data from the web survey were saved automatically. The data were analyzed by factor analysis and regression analysis. Descriptive statistics supplied the mean and standard deviation of the participants' attitude (positive or negative) toward the adjectives. Interrater agreement was used to show the levels of homogeneity in the ratings of adjectives by the participants. Confirmatory and exploratory 385 factor analysis was used to compare the U.S. results with those of the original South Korean data on the 30 adjectives and 13 home pages (Kim et al., 2003). Regression analysis was used to evaluate the influence of individual and combinations of design factors to determine their aesthetic importance to U.S. participants. By building the regression model we were able to understand the relation among design factors and aesthetic responses. The survey results for the South Korean participants came from the original Kim et al. study.

\section{RESULTS}

Hypothesis 1 states that U.S. and South Korean participants will consistently use adjectives with similar meanings to describe home pages that are representative of South Korean web design. With regard to Hypothesis 1, the interrater agreement 
was nearly perfect: $r_{w g}$ was equal to .92 for the U.S. ratings of the 13 home pages using the 30 adjectives. This coincided with the interrater agreement among the South Korean participants in the original study $\left(r_{w g}=.92\right)$. This high level of agree- ment shows that the participants within each group consistently used adjectives 400 with similar meanings in describing the home pages, thus supporting $\mathrm{H} 1$.

Hypothesis 2 states that U.S. and South Korean participants will apply adjectives with different meanings for each aesthetic dimension while viewing the same home pages that are representative of the South Korean web design. For this hypothesis, factor analysis was conducted in two steps. First, confirmatory factor 405 analysis was used to test the reliability and validity of the model established by Kim et al. (2000) as applied to the U.S. data. Table 1 shows the construct loadings for the U.S. ratings of the 30 adjectives. By several goodness-of-fit indices, the results indicate that the 30 adjectives in the U.S. data do not fit the South Korean model nearly as well as the South Korean data, $\chi^{2}=3252.46$, goodness-of-fit $=410$ 0.76 , adjusted goodness-of-fit $=0.66$, root mean residual $=0.147$ (Chin \& Todd, 1995; Gefen, Straub, \& Boudreau, 2000; Hair, Anderson, Tatham, \& Black, 1998; Segars \& Grover, 1993). Moreover, several of the Cronbach's alpha coefficients are well below the standard 0.7 threshold as indicated by the bright, tense, static, popular, simple, and mystic dimensions. It seems unlikely that such a poor fit could be solely attributed to differences in nuance between the meaning of the original Korean adjective and its English counterpart.

The main difference in comparing the results of the analysis of U.S. and Korean data concerns how the U.S. participants applied the translated adjectives to the home pages: The U.S. data could not be grouped into the same dimensions as 420 those selected by the South Korean participants. For example, plain did not fit in the dimension of bright; sharp did not go with tense; static and balanced did not share the same homogeneities with calm; sexy was not matched with colorful and vibrant; and vague did not match mystic. Hence, the result of the confirmatory factor analysis suggested that U.S. participants had a different notion for aesthetic dimension 425 while viewing the same home pages designed by South Korean web developers.

As a result of these findings, a second and more detailed examination was conducted by using exploratory factor analysis. This principal components method, which is an unsupervised method of dimensionality reduction, highlights similarIties and differences in data (Smith, 2002).

During this factor analysis, the U.S. data for the 13 home pages were mathemat- ically rotated using the varimax rotation to reveal six aesthetic dimensions. (South Korean data had likewise revealed six aesthetic dimensions.) Each adjective's factor scores were used to calculate the dependent variables for the follow-up regression analysis. For the U.S. survey results, the first aesthetic dimension 435 explained $21.28 \%$ of the variance, and the remaining five aesthetic dimensions explained $8.42 \%, 6.28 \%, 4.64 \%$, $4.35 \%$, and $3.80 \%$, respectively. From the South Korean survey results, the first aesthetic dimension explained $24.43 \%$ of vari- ance, and the remaining five aesthetic dimensions explained $17.73 \%, 7.61 \%, 6.32 \%, 5.30 \%$, and $3.66 \%$, respectively.

Hence, the factor analysis showed that when comparing the U.S. and South Korean results, the aesthetic dimensions contained different adjectives, thus supporting H2 (Tables 1, 2, and 3). For example, although powerful, sharp, and strong 


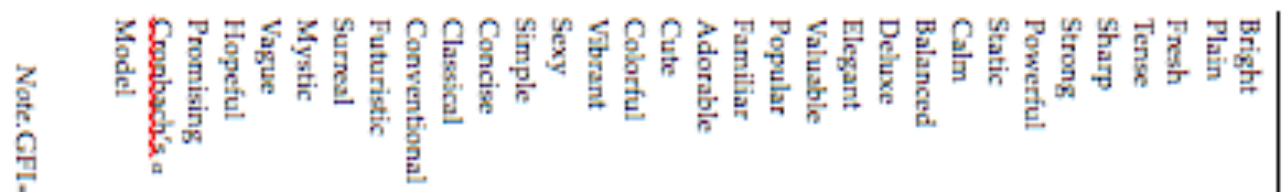

,

究里

西

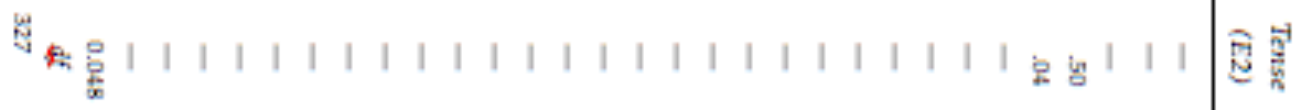

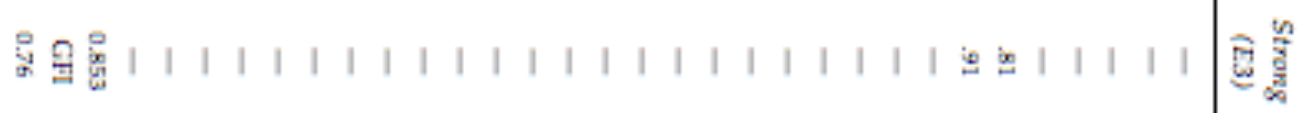

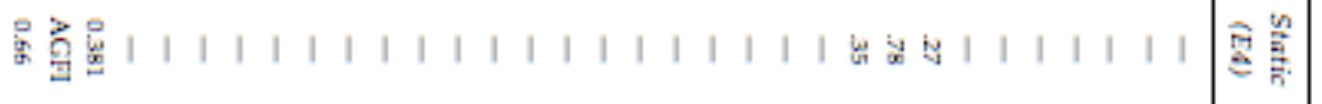

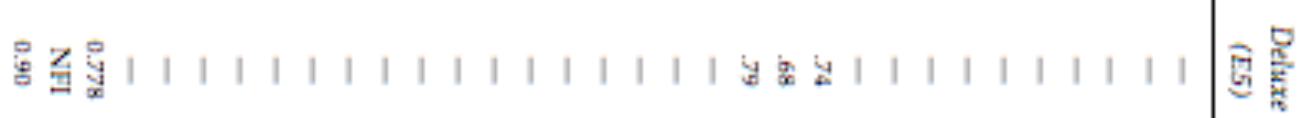

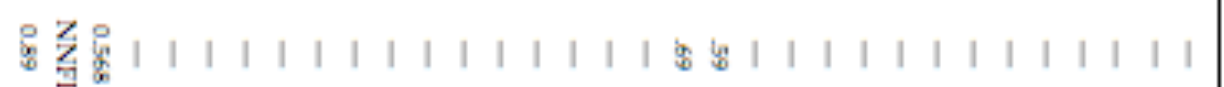

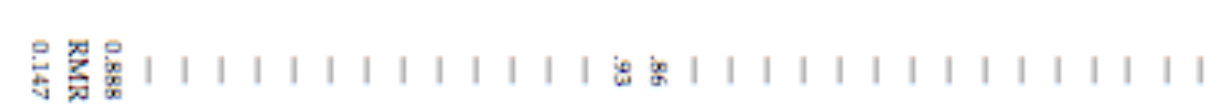

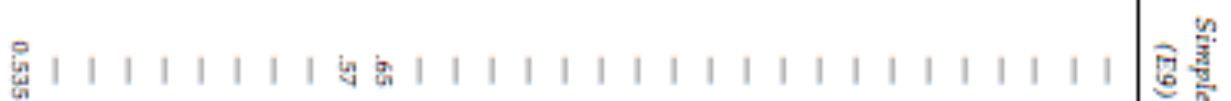

의.| | | | | |

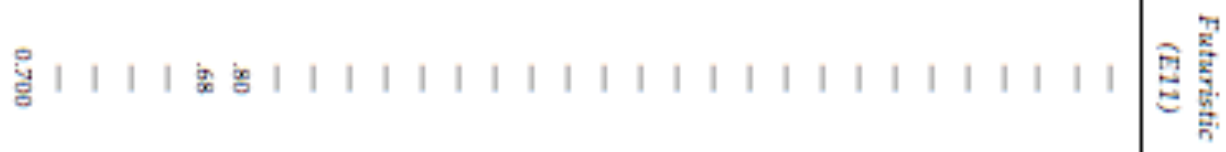

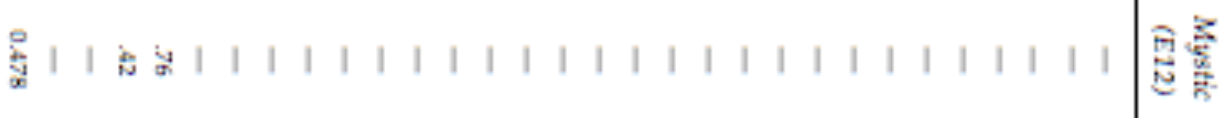

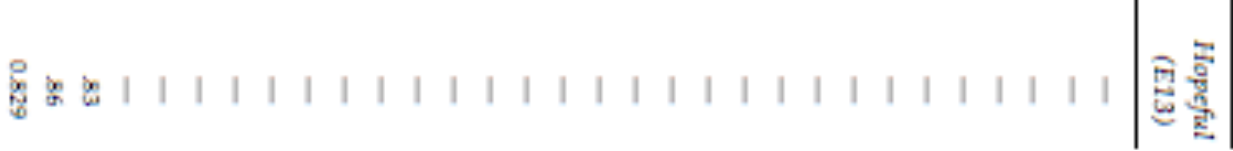


Table 2: Rotated Factor Matrix for U.S. Survey Data: ${ }^{a}$ Extraction Method: Principal Component Analysis; Rotation Method: Varimax With Kaiser Normalization

\begin{tabular}{|c|c|c|c|c|c|c|}
\hline & \multicolumn{6}{|c|}{ Factor (Aesthetic Dimension) } \\
\hline & 1 & 2 & 3 & 4 & 5 & 6 \\
\hline Powerful & .67 & -.10 & .26 & .03 & .19 & -.07 \\
\hline Deluxe & .67 & .00 & .04 & .08 & .03 & .21 \\
\hline Valuable & .62 & .34 & .01 & .06 & -.07 & .11 \\
\hline Strong & .62 & -.03 & .26 & .04 & .22 & -.08 \\
\hline Promising & .60 & .37 & .07 & .05 & -.07 & .11 \\
\hline Fresh & .60 & .01 & .09 & .12 & .08 & .10 \\
\hline Sharp & .59 & .11 & -.06 & .19 & .09 & .01 \\
\hline Popular & .58 & .23 & -.03 & .04 & .05 & .27 \\
\hline Elegant & .55 & .21 & .11 & .18 & -.05 & .10 \\
\hline Hopeful & .47 & .34 & -.08 & .15 & .03 & .33 \\
\hline Familiar & .17 & .69 & .08 & .08 & .05 & -.02 \\
\hline Conventional & .06 & .66 & .07 & .02 & .25 & .00 \\
\hline Classical & .20 & .61 & -.09 & .05 & .19 & .13 \\
\hline Calm & .13 & .46 & -.07 & .15 & .27 & .16 \\
\hline Concise & .30 & .33 & .18 & .00 & .25 & .09 \\
\hline Surreal & .08 & .06 & .73 & .11 & -.05 & .03 \\
\hline Mystic & .15 & .04 & .72 & .01 & -.11 & .04 \\
\hline Futuristic & .06 & .09 & .56 & .31 & -.01 & -.06 \\
\hline Tense & .15 & -.42 & .49 & .04 & .13 & -.04 \\
\hline Vague & .00 & -.04 & .47 & -.09 & .21 & .12 \\
\hline Bright & .12 & .02 & .05 & .76 & .13 & .03 \\
\hline Colorful & .11 & .18 & .04 & .73 & .16 & .13 \\
\hline Vibrant & .37 & .00 & .21 & .66 & .06 & .10 \\
\hline Plain & -.05 & .27 & -.01 & .07 & .72 & .02 \\
\hline Simple & .20 & .12 & -.01 & .13 & .66 & -.01 \\
\hline Static & .01 & .10 & .06 & .10 & .61 & .17 \\
\hline Balanced & .24 & .16 & .02 & .24 & .28 & -.11 \\
\hline Adorable & .12 & .15 & .01 & .13 & .12 & .79 \\
\hline Cute & .16 & .13 & .05 & .08 & .14 & .77 \\
\hline Sexy & .37 & -.19 & .19 & -.07 & -.16 & .47 \\
\hline
\end{tabular}

${ }^{\text {a }}$ Rotation converged in seven iterations.

were in the first dimension in both groups, deluxe, valuable, promising, fresh, popular, elegant, and hopeful were contained only in the U.S. group, and tense, surreal, 445 futuristic, sexy, mystic, and colorful were contained only in the South Korean group. In addition, U.S. participants treated familiar, conventional, classical, calm, and concise as one aesthetic dimension, whereas South Korean participants divided them among four.

The factor loadings for each adjective in the U.S. data were used as the weights 450 for 30 adjectives and summed into a single index to represent the intensity of the participants' aesthetic responses to South Korean designed home pages. The single index represents the participant's aesthetic responses comprehensively. This index was used as the outcome variable for a regression model (Table 4). Because the results of the factor analysis showed a significant difference between the South Korean and U.S. groups, the regression models used researcher-defined design 
Table 3: Rotated Factor Matrix for South Korean Survey Data ${ }^{a}$ : Extraction Method: Principle Component Analysis; Rotation Method: Varimax With Kaiser Normalization

\begin{tabular}{|c|c|c|c|c|c|c|}
\hline & \multicolumn{6}{|c|}{ Factor (Aesthetic Dimension) } \\
\hline & 1 & 2 & 3 & 4 & 5 & 6 \\
\hline Strong & .80 & -.08 & .04 & .05 & -.01 & -.09 \\
\hline Tense & .80 & -.14 & .02 & .04 & -.12 & -.01 \\
\hline Sharp & .79 & -.16 & .00 & .01 & -.09 & .10 \\
\hline Powerful & .78 & -.03 & .08 & .08 & .14 & -.05 \\
\hline Surreal & .67 & .00 & .01 & .12 & -.38 & -.11 \\
\hline Futuristic & .65 & .08 & .15 & .21 & -.13 & -.25 \\
\hline Sexy & .61 & .25 & -.06 & .16 & -.09 & .20 \\
\hline Mystic & .57 & .11 & .07 & .29 & -.44 & -.03 \\
\hline Colorful & .49 & .43 & -.14 & .23 & .25 & -.11 \\
\hline Cute & .00 & .86 & .09 & .01 & .01 & .17 \\
\hline Adorable & .03 & .85 & .09 & .02 & -.01 & .16 \\
\hline Bright & -.18 & .69 & .27 & .18 & .16 & -.06 \\
\hline Fresh & -.15 & .67 & .33 & .29 & .09 & .02 \\
\hline Vibrant & .47 & .51 & .01 & .20 & .23 & -.12 \\
\hline Hopeful & .13 & .50 & .31 & .30 & .31 & -.08 \\
\hline Simple & .06 & .15 & .84 & .02 & .13 & .00 \\
\hline Concise & .07 & .16 & .83 & .03 & .17 & .02 \\
\hline Static & .06 & .19 & .69 & .31 & .14 & -.12 \\
\hline Balanced & .08 & .08 & .61 & .31 & .21 & -.06 \\
\hline Elegant & .24 & .13 & .10 & .81 & .04 & .16 \\
\hline Valuable & .31 & .18 & .10 & .78 & .03 & .16 \\
\hline Deluxe & .34 & .09 & .21 & .74 & .04 & .00 \\
\hline Plain & -.17 & .46 & .27 & .52 & -.12 & .20 \\
\hline Calm & -.14 & .14 & .47 & .49 & -.18 & .23 \\
\hline Vague & .29 & -.01 & -.13 & -.03 & -.65 & .14 \\
\hline Familiar & -.12 & .19 & .31 & .03 & .63 & .30 \\
\hline Popular & -.07 & .21 & .35 & -.02 & .63 & .26 \\
\hline Promising & .14 & .15 & .35 & .39 & .43 & $.03^{\mathrm{a}}$ \\
\hline Conventional & -.08 & .08 & -.06 & .11 & .05 & .87 \\
\hline Classical & -.03 & .08 & -.01 & .21 & .11 & .84 \\
\hline
\end{tabular}

${ }^{\mathrm{a}}$ Rotation converged in eight iterations.

elements as predictor variables instead of the original design factors defined by the Kim et al. (2003) study.

In the first equation, male participants preferred positive adjectives to describe home pages with an $R^{2}$ of .11 . The second equation examined the relation between gender and age and home page design elements. This equation showed that partic460 ipants preferred icons, frames, and margins and had less preference for navigation bars and typography with an $R^{2}$ of .36. U.S. participants may have reacted negatively to the South Korean text because they could not read Hangul. This may explain the large negative coefficient for typography. This increase in $R^{2}$ confirms the effectiveness of exploiting design factors in home pages, which increases the aesthetic rating from the standpoint of interaction design.

The third equation examined only the relation between gender and age and the dominant and secondary color factors. The results showed that participants 
Table 4: Regression Analysis from U.S. Survey Results for Predicting Aesthetics With Demographics, Design Elements, and Color

\begin{tabular}{|c|c|c|c|c|}
\hline & \multicolumn{4}{|c|}{ Aesthetics } \\
\hline & 1 & 2 & 3 & 4 \\
\hline Gender & $-3.01^{* *}$ & $-2.91^{* *}$ & $-3.07^{* *}$ & $-2.85^{* *}$ \\
\hline Age & -.70 & -.83 & -.83 & -.86 \\
\hline Design: Navigator & - & -1.72 & - & $10.13^{*}$ \\
\hline Design: Icons & - & $5.83^{* * *}$ & - & $3.61^{*}$ \\
\hline Design: Frames & - & 3.19 & - & -3.62 \\
\hline Design: Margin & - & $4.54^{*}$ & - & $9.19^{* *}$ \\
\hline Design: Typography & - & $-10.63^{* * *}$ & - & 7.79 \\
\hline Dominant color: Red & - & - & $9.53^{* * *}$ & 7.14 \\
\hline Dominant color: Green & - & - & $8.61^{* * *}$ & 3.46 \\
\hline Dominant color: Blue & - & - & $14.63^{* * *}$ & $18.33^{* *}$ \\
\hline Secondary color: Red & - & - & $-8.28^{* *}$ & 4.67 \\
\hline Secondary color: Green & - & - & $-11.65^{*}$ & -20.68 \\
\hline Secondary color: Blue & - & - & $-10.79^{* *}$ & -12.85 \\
\hline$F$ & 4.03 & 14.28 & 10.47 & 10.35 \\
\hline$R^{2}$ & .11 & .36 & .33 & .41 \\
\hline
\end{tabular}

Note. Values represent unstandardized coefficients.

${ }^{*} p<.05 .{ }^{* *} p<.01 .{ }^{* * *} p<.001$.

preferred contrasting colors. The addition of dominant and secondary color factors increased the $R^{2}$ to .33 . These results show that home pages with a higher contrast between dominant and secondary colors will have a higher aesthetic rating. The last equation examined gender and age, home page design elements, and dominant and secondary color factors. This combination of factors resulted in an $R^{2}$ of .41. These results show that design factor will have a greater influence on aesthetic intensity when combining design factors and high-color contrasts. Navigation bars, icons, and margins were also important design factors in the aesthetic perceptions of vivid home pages.

\section{DISCUSSION AND CONCLUSION}

Research suggests that cultural experiences shape emotional development and, 480 in turn, the formation of aesthetic sensibilities (Marcus \& Gould, 2000; Sheridan, 2001; Singh \& Baack, 2004). Recent research has also examined the influence of culture on web design by comparing the judgments of participants from diverse cultures (Hillier, 2003; Yetim \& Raybourn, 2003; Zahedi, van Pelt, \& Song, 2001). These studies provide computational models that show trends and comparisons of the data that can help to draw conclusions regarding the influence of culture on local developers and users of websites. These studies also point to the need to revisit issues, such as cultural sensitivity with regard to emotional responses to web aesthetics (Brave \& Nass, 2003; Fogg, 2003; Gobé, 2001).

The present study investigated web home pages with targeted secondary emotions from a cross-cultural perspective, that is, by comparing U.S. and South 
Korean participants. Using the original 30 emotional adjectives from the Kim et al. (2003) study, U.S. participants viewed the same 13 South Korean-designed home pages. Some emotive adjectives were more related to emotions, whereas others were more related to aesthetic responses, as outlined by Kim et al.

The results of this study indicate that U.S. and South Korean participants consistently used emotive adjectives with similar meanings to describe home pages within their own group. However, the main aesthetic dimensions (design factors) used by U.S. and South Korean participants to describe the same home pages contained sets of adjectives with different meanings. From the standpoint of cross-cultural web aesthetics, several design factors increased the U.S. participants' emotional response (or ratings) to web aesthetics according to the regression model. Hence, in comparing the two cultural samples, the findings demonstrate the influence of culture on aesthetic judgments about web home pages, as well as the complexity of aesthetic responses with respect to cultural differences. The find- 505 ings presented here provide useful insights to web designers who serve a global community.

\section{REFERENCES}

Angeli, A. D., Sutcliffe, A., \& Hartmann, J. (2006). Interaction, usability and aesthetics: What influences users' preferences? In Proceedings of Designing Interactive Systems 2006 (pp. 510 271-280). New York, NY: ACM.

Arnheim, R. (1986). New essays on the psychology of art. Berkeley: University of California Press.

Averill, J. R. (1994). In the eyes of the beholder. In P. Ekman \& R. J. Davidson (Eds.), The nature of emotion: Fundamental questions (pp. 7-14). Oxford, UK: Oxford University Press.

Badre, A. N. (2000). The effects of cross cultural interface design orientation on World Wide Web user performance. Retrieved from http://www.cc.gatech.edu/gvu/reports/2001/ abstracts/01-03.html/

Ben-Bassat, T., Meyer, J., \& Tractinsky, N. (2006). Economic and subjective measures of the perceived value of aesthetics and usability. ACM Transactions on Computer-Human Interaction, 13, 210-234.

Bickmore, T. W., \& Picard, R. W. (2005). Establishing and maintaining long-term humancomputer relationships. ACM Transactions on Computer-Human Interaction, 12, 293-327.

Biehl, M., Matsumoto, D., Ekman, P., Hearn, V., Heider, K., Kudoh, T., \& Ton, V. (1997). Matsumoto and Ekman's Japanese and Caucasian facial expressions of emotion): Reliability data and cross-national differences. Journal of Nonverbal Behavior, 21(1),3-21.

Blythe, M., Overbeeke, K., Monk, A.F., \& Wright, P. (Eds.), (2004). Funology: From usability to enjoyment. New York, NY: Springer-Verlag.

Boucher, J. D., \& Carlson, G. E. (1980). Recognition of facial expression in three cultures. Journal of Cross-Cultural Psychology, 11, 263-280.

Brave, S., \& Nass, C. (2003). Emotion in human-computer interaction. In J. A. Jacko \& A. Sears (Eds.), The human-computer interaction handbook: Fundamentals, evolving technologies, and emerging applications. Mahwah, NJ: Erlbaum.

Buck, R. (1999). The biological affects: A typology. Psychological Review, 106, 301-336.

Burnett, G.., \& Buerkle, H. (2004). Information exchange in virtual communities: A comparative study. Journal Computer-Mediated Communication, 9(2). Retrieved from http://jcmc.indiana.edu/vol9/issue2/burnett.html/ 
Chau, P. Y. K., Cole, M., Massey, A. P., Montoya-Weiss, M., \& O’Keefe, R. M. (2002). Cultural differences in the online behavior of consumers. Communications of the ACM, 45(10), $540138-143$.

Chin, W. W., \& Todd, P. A. (1995). On the use, usefulness, and ease of use of structural equation modeling in MIS research: A note of caution. MIS Quarterly, 19, 237-246.

Cole, M., Gay, J., Glick, J. A., \& Sharp, D. W. (1971). The cultural context of learning and thinking. New York, NY: Basic Books.

Cupchik, G. C. (1994). Emotion in aesthetics: Reactive and reflective models. Poetics, 23(1), 177188.

Cyr, D., \& Trevor-Smith, H. (2004). Localization of Web design: A comparison of German, Japanese, and US website characteristics. Journal of the American Society for Information Science and Technology, 55, 1199-1208.

Doost, H., Moradi, A., Tagahavi, M., Yule, W., \& Dalglesh, T. (1999). The development of a corpus of emotional words produced by children and adolescents. Personality and Individual Difference, 27, 433-451.

Dorai, C., \& Venkatesh, S. (2002). Media computing: Computational media aesthetics. Boston, MA: Kluwer Academic.

Dou, W., Nielsen, U., \& Ming, T. C. (2002). Using corporate Web sites for export marketing: A multi-country comparison. Journal of Advertising Research, 42, 105-115.

Ekman, P. (1992). An argument for basic emotions. Cognition and Emotion, 6, 169-200. Ekman, P.

(1994). Antecedent events and emotion metaphors. In P. Ekman \& R. Davidson

(Eds.) The nature of emotion: Fundamental questions. (pp. 146-149). New York, NY: Oxford University Press.

Ekman, P. (1999). Handbook of cognition and emotion. Sussex, UK: Wiley \& Sons.

Faiola, A., \& MacDorman, K. (2008). Exploring the influence of web designer cognitive style on information design: A cross-cultural comparison of a holistic and analytical perspective. Information, Communication and Society, 11, 348-374.

Faiola, A., \& Matei, S. A. (2005). Cultural cognitive style and web design: Beyond a behav- ioral inquiry into computer-mediated communication. Journal of Computer-Mediated Communication, 11(1), article 18. Retrieved from http://jcmc.indiana.edu/vol11/issue1/ faiola.html

Fogg, B. J. (2003). Persuasive technology: Using computers to change what we think and do. Boston, MA: Morgan Kaufman.

Frijda, N. H. (1989). Aesthetic emotions and reality. American Psychologist, 44, 1546-1547. Gaunt,

R. L., Leyens, J. P., \& Demoulin, S. (2002). Intergroup relations and the attribution of emotions: Control over memory for secondary emotions associated with the ingroup and outgroup. Journal of Experimental Social Psychology, 38, 508-514.

Gefen, D., Straub, D., \& Boudreau, M. (2000). Structural equation modeling and regression: Guidelines for research practice. Communications of the Association for Information Systems, 4, $1-79$.

Geissler, G. L. (1998). The World Wide Web as an advertising medium: A study of communication effectiveness. Athens: The University of Georgia Press.

Gobé, M. (2001). Emotional branding: The new paradigm for connecting brands to people. New York, NY: Allworth Press.

Gratch, J., \& Marsella, S., (2005). Some lessons for emotion psychology for the design of lifelike characters, Journal of Applied Artificial Intelligence, 19, 215-233.

Hair, J. F., Jr., Anderson, R. E., Tatham, R. F., \& Black, W. C. (1998). Multivariate data analysis with readings (5th ed.). Englewood Cliffs, NJ: Prentice Hall.

Hartmann, J. (2006). Assessing the attractiveness of interactive systems. Proceedings of the CHI 2006 Human Factors in Computing Systems (pp. 1755-1758). New YOrk, NY: ACM. 
Hassenzahl, M., Platz, A., Burmester, M., \& Lehner, K. (2000). Hedonic and ergonomic quality aspects determine a software's appeal. Proceedings of CHI 2000 Extended Abstracts (pp. 590 201-208). New York, NY: ACM.

Heijden, H. v. d. (2003). Factors influencing the usage of websites: The case of a generic portal in The Netherlands, Information Management, 40, 541-549.

Hillier, M. (2003). The role of cultural context in multilingual website usability. Journal of Electronic Commerce Research and Applications, 2, 2-14.

Hofstede, G. (1980). Culture's consequences: International differences in work-related values. Newbury Park, CA: Sage.

Hofstede, G. (1991). Cultures and organizations: Software of the mind: Intercultural cooperation and its importance for survival. Cambridge, England: McGraw-Hill.

Igbaria, M., \& Zviran, M. (1996). Comparison of end-user computing characteristics in the US, Israel and Taiwan. Information and Management, 30(1), 1-13.

Izard, C. E. (1971). The face of emotion. New York, NY: Appleton-Century-Crofts. Kamppuri, M.,

Bednarik, R., \& Tukiainen, M. (2006). The expanding focus of HCI: Case culture. Proceedings of the 4th Nordic Conference on Human-Computer Interaction: Changing roles (pp. 405-408). New York, NY: ACM.

Karsvall, A. (2002). Personality preferences in graphical interface design. Proceedings of the ACM Second Nordic Conference on Human-Computer Interaction (pp. 217-218). New York, NY: ACM.

Karvonen, K. (2000). The beauty of simplicity, Proceedings of the ACM Conference on Universal Usability (pp. 85-90). New York, NY: ACM.

Kim, J., Lee, J., \& Choi, D. (2003). Designing emotionally evocative homepages: An empiri- cal study of the quantitative relations between design factors and emotional dimensions. International Journal of Human-Computer Interaction Studies, 59, 899-940.

Kim, J., \& Moon, J. Y. (1997). Emotional usability of customer interfaces: Focusing on cyber banking system interfaces. Proceedings of the Human Factors in Computing Systems: Looking to the future (pp. 283-284). New York, NY: ACM.

Lavie, T., \& Tractinsky, N. (2004). Assessing dimensions of perceived visual aesthetics of Web sites. International Journal of Human-Computer Interaction Studies, 60, 269-298.

Marcus, A. (2003). Global and intercultural user-interface design. In J. A. Jacko \& A. Sears (Eds.), The human-computer interaction handbook: Fundamentals, evolving technologies, and emerging applications. Mahwah, NJ: Erlbaum.

Marcus, A., \& Gould, E. W. (2000). Crosscurrents cultural dimensions and global web user interface design. Interactions, 2(4), 32-46.

Matsumoto, D. (1992). American-Japanese cultural differences in the recognition of universal facial expressions. Journal of Cross-Cultural Psychology, 23(1), 72-84.

Matsumoto, D., \& Ekman, P. (1989). American-Japanese cultural differences in intensity ratings of facial expressions of emotion. Motivation and Emotion, 13, 143-157.

McAndrew, F. T. (1986). A cross-cultural study of recognition thresholds for facial expres- sions of emotion. Journal of Cross-Cultural Psychology, 17, 211-224.

Murphy, P. D., \& Kraidy, M. M. (Eds.). (2003). Global media studies: Ethnographic perspectives. London, UK: Routledge.

Nakarada-Kordic, I., \& Lobb, B. (2005). Effect of perceived attractiveness of web interface design on visual search of web sites. In: Proceedings of CHINZ05, the ACM SIGCHI New Zealand Chapters International Conference on Computer-Human Interaction 2005 (pp. 25-27). New York, NY: ACM.

Nisbett, R. E. (2003). The geography of thought. New York, NY: The Free Press.

Nisbett, R. E., \& Norenzayan, A. (2002). Culture and cognition. In D. Medin \& H. Pashler (Eds.), Steven's handbook of experimental psychology: Memory and cognitive processes. New York, NY: Wiley \& Sons. 
Norman, D. (2004). Emotional design: Why we love (or hate) everyday things. New York, NY: Basic Books.

Oatley, K., \& Johnson-Laird, P. N. (1987). Towards a cognitive theory of emotions. Cognition and Emotion, 1(1), 29-50.

Omar, M. (1992) Attitudes of college students towards computers: a comparative study in the United States and the Middle East. Computers in Human Behavior, 8, 249-257.

Pagulayan, R. J., Keeker, K., Wixon, D., Romero, R. L., \& Fuller, T. (2003). User-centered design in games. In J. A. Jacko \& A. Sears (Eds.), The human-computer interaction handbook: Fundamentals, evolving technologies, and emerging applications. Mahwah, NJ: Erlbaum.

Picard, R. W. (1997). Affective computing. Cambridge, MA: MIT Press.

Picard, R. W., Papert, S., Bender, W., Blumberg, B., Breazeal, C., Cavallo, D., .. S Strohecker, C. (2004). Affective learning: A manifesto. BT Technology Journal, 22, 253-269.

Reeves, B., \& Nass, C. (1998). The media equation: How people treat computers, television, and new media like real people and places. Stanford, CA: CSLI.

Rosenberg, E. L. (1998). Levels of analysis and the organization of affect. Review of General Psychology, 2, 247-270.

Rosenberg, E. L., \& Ekman, P. (1994). Coherence between expressive and experiential systems in emotion. Cognition and Emotion, 8, 201-229.

Schenkman, B. N., \& Jonsson, F. U. (2000). Aesthetics and preferences of Web pages. Behaviour \& Information Technology, 19, 367-377.

Segars, A. H. \& Grover, V. (1993). Re-Examining perceived ease of use and usefulness: A confirmatory factor analysis. MIS Quarterly 17, 517-525.

Shen, S., Woolley, M., \& Prior, S. (2006). Towards culture-centred design. Interacting with Computers, 18, 820-852.

Sheridan, E. F. (2001). Cross-cultural web-site design: Multilingual computing and technology. Multilingual Computing, 12(7), 53-56.

Simon, S. J. (1999). A cross cultural analysis of Web site design: An empirical study of global Web users. Retrieved from http://marketing.byu.edu/htmlpages/ccrs/proceedings $99 /$ simon.htm

Singh, N., \& Baack, D. (2004). Web site adaptation: A cross-cultural comparison of U.S. and Mexican web sites. Journal of Computer-Mediated Communication, 9(4). Retrieved from http://jcmc.indiana.edu/vol9/issue4/singh_baack.html/

Singh, N., Fassott, G., Zhao, H., \& Boughton, P. D. (2006). A cross-cultural analysis of German, Chinese and Indian consumers' perception of Web site adaptation. Journal of Consumer Behaviour, 5(1), 56-68.

Smith, L. I. (2002). A tutorial on principal component analysis. Retrieved from http:// csnet.otago.ac.nz/cosc453/student_tutorials/principal_components.pdf/

Spiller, F. (2005). Demystifying usability: How many users should you test with in usability testing? Retrieved from http://experiencedynamics.blogs.com/site_search_ usability/2005/01/latest_research.html/

Sutcliffe, A. (2003). Multimedia user interface design. In J. A. Jacko \& A. Sears (Eds.), 680 The human-computer interaction handbook: Fundamentals, evolving technologies, and emerging applications. Mahwah, NJ: Erlbaum.

Tractinsky, N. (2004). Towards the study of aesthetics in information technology. Proceedings of the 25th Annual International Conference on Information Systems (pp. 771-780). New York, NY: ACM.

Travis, D. (2000). Emotional branding: How successful brands gain the irrational edge. Roseville, CA: Prima Venture.

Watzman, S. (2003). Visual design principles for usable interfaces. In J. A. Jacko \& A. Sears (Eds.), The human-computer interaction handbook: Fundamentals, evolving technologies, and emerging applications. Mahwah, NJ: Erlbaum. 
Yetim, F., \& Raybourn, E. M. (2003). Supporting intercultural computer-mediated discourse: Methods, models, and architectures. CHI Extended Abstracts (pp. 1054-1055). New York, NY: ACM.

Zahedi, F., Van Pelt, W., \& Song, J. (2001). A conceptual framework for international web design. IEEE Transactions on Professional Communication, 44, 83-103.

Zettl, H. (1990). Sight, sound, motion: Applied media aesthetics. Belmont, CA: Wadsworth. Zettl, H. (2002). Essentials of applied media aesthetics. In C. Dorai \& S. Venkatesh (Eds.), Media computing: Computational media aesthetics. Boston, MA: Kluwer Academic. 